Saudi Journal of Humanities and Social Sciences

Abbreviated Key Title: Saudi J Humanities Soc Sci

ISSN 2415-6256 (Print) | ISSN 2415-6248 (Online)

Scholars Middle East Publishers, Dubai, United Arab Emirates

Journal homepage: https://saudijournals.com/sjhss

Original Research Article

\title{
Perceived Stress among Health Care Providers in Long Term Care Facilities
}

\author{
Ms, Sruthi Sivaraman ${ }^{1 *}$, Dr. Sherin P Antony ${ }^{2}$ \\ ${ }^{1}$ Research Scholar, Dept. of Psychology, Jain University, Bangalore, India \\ ${ }^{2}$ Research Supervisor, Dept. of Psychology, Jain University, Assistant Professor at Christ University Bangalore, India
}

DOI: $10.36348 /$ sihss.2020.v05i10.012

| Received: 05.10.2020 | Accepted: 17.10.2020 | Published: 29.10.2020

*Corresponding author: Sruthi Sivaraman

\section{Abstract}

The study was conducted to analyze the effect of self-care intervention on perceived stress of health care providers of elderly with Dementia during the COVID19 pandemic. The objective is find out the outcome of the Self-care intervention on perceived stress of health care providers in long term care facilities. 50 Health care providers of elderly with Dementia are chosen based on purposive sampling. Male and female formal health care providers aged about 20-35yrs who can comprehend Kannada, Tamil, Malayalam and English with an experience of at least 1 month. On an average the perceived stress was higher in the participants prior to the intervention. The study has shown the inevitable benefits of self-care program in modifying aspects of training for the health care workers by identifying perceived stress in maintaining a greater personnel strength and their health promotion. It is concluded that Self-care program aids in subsiding the levels of perceived stress even in situations demanding high levels of occupational dedication in health care workers.

Keywords: Dementia, COVID19 pandemic, self-care, Self- management.

Copyright () 2020 The Author(s): This is an open-access article distributed under the terms of the Creative Commons Attribution 4.0 International License (CC BY-NC 4.0) which permits unrestricted use, distribution, and reproduction in any medium for non-commercial use provided the original author and source are credited.

\section{INTRODUCTION}

WHO has defined "self-care" as "the ability of individuals, families and communities to promote health, prevent disease, maintain health, and to cope with illness and disability with or without the support of a health-care provider". As the term self-care promotes health, it seemed important to facilitate the self-care program during the pandemic.

Formal carers are personnel trained to provide services for family carers including a respite from the sense of burden and demanding continued caring [1]. Formal care that occurs in collaboration with the family and the care receiver may benefit the seekers. The mode of formal care delivery is important as it would influence the well-being of the family and care recipient [2]. The literature suggests that culturally sensitive policies will incorporate training for both family members and formal care workers [3].

As Covid19 continues to pose unprecedented challenges to residential care facilities especially those caring for persons with dementia, formal caregivers of persons with dementia had various needs during the pandemic. It is hard to ignore their needs as it would affect their well-being also reflect in the quality of care of the care recipient. The caregivers were concerned about being infected with the Covid19 and secluded away from their relatives as they were working with the very much vulnerable population who don't remember to follow the etiquettes and hand hygiene.

In 2013, WHO had advised organisations to develop health programs for prevention of hypertension and associated comorbidities in employees. Enhancing health aspects in employees may enhance productivity, reduce absenteeism and turn-over and engage the employees through a demonstrated commitment to their well-being [4]. There is scarcity of health prevention interventions conducted in workplace, especially in India.

Aim

To find out the outcome of the Self-care intervention on perceived stress of health care providers of elderly with Dementia during the COVID19 pandemic 


\section{Objectives}

To find out the differences in the levels of perceived stress pre and post the Self-care intervention for health care providers of elderly with dementia during the COVID19 pandemic.

\section{Hypothesis}

There is no significant difference in perceived stress of health care providers of elderly with dementia before and after the self-care intervention during the COVID19 pandemic.

\section{MATERIALS AND METHODS}

Participants: 50 Health care providers of elderly with Dementia who belonged to 20-35years of age were selected from different residential care units of Bangalore.

\section{Sampling: Purposive Sampling}

\section{Inclusion Criteria}

Male and female health care providers

Age 20-35yrs

People who can comprehend Kannada, Tamil, Malayalam and English

Being a health care provider for at least 1 month

\section{Exclusion Criteria}

Health care providers who are working in homecare setup

Health care providers who reported chronic mental health issues

\section{Tools}

The Perceived Stress Scale (PSS) [5]: is one of the psychological tools used for assessing the perception of stress. It measures the extent to which situations in one's life are considered as stressful. Items were intended to identify how random, overwhelming, and burdened respondents find their lives. The scale seeks information about the feelings and thoughts of the participants during the last 30 days. PSS composed of 10 items in a Likert scale of five points, ranging from "never" to "always." The questions are divided into seven positive and seven negative ones. The scores are obtained by reversing responses (e.g., $0=4,1=3,2=$ $2,3=1 \& 4=0$ ) to the four positively stated items (items $4,5,7, \& 8$ ). The total of the scale was obtained from the sum of the scores of the 14 items and the scores ranged from 0 to 56 .

\section{Ethical Considerations}

- All ethical guidelines by APA for intervention practice was kept in mind during the research

- The respect and dignity of every participant was a priority throughout the research study.

- Initially information about the research and purpose of the intervention was explained to the participants. Only those who were comfortable with the process was included.
- Anonymity of all participants and their organizations were ensured.

- All the measures for followed to avoid discomfort in the participants

- Every session during the intervention included a debriefing with the participants.

\section{Research Design}

The design is a single group pre-posttest research design.

\section{Procedure}

50 Formal caregivers of persons with Dementia who belong to 20-35years of age were selected from different residential care units of Bangalore through purposive sampling and PSS was administered after seeking the informed consent.

\section{Rationale for Intervention}

An unstructured interview was conducted in view of the lockdown announcements and the surge in Covid19 pandemic. The group of health care providers reported high levels of ambiguity during the unstructured interview. This lead to the implementation of the research. The researcher assessed their perceived stress and the intervention was designed to help in managing the perceived stress hence regular actions could be taken to stay healthy. The sessions of self-care program were conducted and monitored over a period of 6 weeks. Each session lasted for $2 \mathrm{hrs}$ divided into 2 section of an hour each.

\section{Self-care module has been planned under three aspects}

1. Self-care at management of work, dealing with the person with dementia.

2. Self-care at space: safety measures (reduce the risk and triggering factors that induce fear and anxiety)

3. Self-care in the management of emotions. Increasing the protective factors.

First section covered the preparedness of COVID19 management in the residential care units of persons with dementia and the second section covered aspects of self-care model.

The first session included awareness and experiential learning of safety measures of COVID-19. At the end of this session Jacobson's deep muscle relaxation technique was taught and practiced. The focus of this session was to bring their focus to more on to the bodily awareness and breathing that lead to alleviate anxiety and fear. This aim of the JPMR was to bring their confidence in regulation their anxiety and fear.

The focus of the second session was on

i) Self- management: This session was related to identifying warning signs of stress and facilitating the 
group learning to discover healthy stress management practices

ii) Improving the negative sense through sensory awareness and feedback: In this session participants were engaged in mindful practices of nurturing one's own sensory experiences to the forefront concentration of the individual (ex: smell of jasmine, sounds fresh rain, walking in the sea).

iii) Simplifying their routine: This session included feedback from the health care workers in terms of complexity of the tasks in view of COVID19 and shortage of human resources during lockdown and alterations were made to suit the needs of the persons with dementia after careful analysis of the situation.

iv) Supporting self-affirmations: In this session participants were asked to repeat the following positive affirmations 5 times in the group "I love who I am and what I do", "I am a valued person at my workplace and my voice is always heard respectfully", "I take necessary precautions and release the need to worry", "I focus on what I can control and change instead of what I can't'. After this deep breathing was practiced.

v) Articulating their strengths from the positive moments: The participants were asked to talk about one of their achievements in the last week and to identify their strengths that has helped them to combat the challenge positively.

vi) Concentrating on physical activities: In this session participants were asked to participate in kabaddi, throw ball and skipping for 45 minutes. 15 minutes of reflection on the team spirit was practiced.

vii) Dietary benefits: Minor changes in the diet was done and every day check on and meal planning including proteins and recipes of their choice was implemented to avoid skipping meals.

viii) Psychological counselling: Psychological counselling was offered once a week to everyone at least once in a week to address their grief, guilt, contempt, shock and hopelessness due to the changes in the life events.

\section{Data Collection}

Pre-data were collected. Self-care program was conducted over a period of 2 months. After a gap of 10 days the post data was collected. The data was subjected to statistical analysis. Since the data have been tested and fall under normal probability paired $t$ test has been employed to find out the significant differences between the pre and post data.

\section{Statistical Analysis}

Quantitative analysis was employed for all the measures used. Descriptive statistics such as mean, standard deviation is used to analyse the data. Paired sample test is carried out to find out the difference in the perceived stress level pre and post the intervention.

\section{RESULTS AND DISCUSSIONS}

Stress involves various dimensions and multifaceted theory and can be measured from different concepts, such as the environmental, biological and psychological ones [6-8]. The analysis of the result shows that out of 50 participants 48 of them are females and 2 of them are males. Elevated stress levels are noted in female health care workers [9]. The sociodemographic characteristics found were similar to the ones in previous studies, with health care professionals $[9,10]$. Perceived Stress may not be manipulated by age, education and income during the pandemic.

Table-1: Showing descriptive statistics

\begin{tabular}{|c|c|c|c|c|}
\hline \multirow{2}{*}{ Item } & \multicolumn{2}{|c|}{ Pre } & \multicolumn{2}{c|}{ Post } \\
\cline { 2 - 5 } & Mean & SD & Mean & SD \\
\hline 1 & 3.64 & 0.56 & 3.08 & 0.77 \\
\hline 2 & 3 & 0.94 & 2.68 & 1.08 \\
\hline 3 & 3.08 & 0.75 & 2.66 & 1.22 \\
\hline 4 & 0.94 & 1.04 & 1.28 & 1.13 \\
\hline 5 & 1.64 & 0.94 & 1.66 & 1.15 \\
\hline 6 & 2.64 & 0.89 & 2.26 & 1.12 \\
\hline 7 & 3.14 & 0.81 & 1.8 & 1.11 \\
\hline 8 & 3.04 & 0.85 & 1.86 & 1.19 \\
\hline 9 & 2.92 & 1.03 & 2.36 & 1.15 \\
\hline 10 & 2.92 & 1.03 & 2.62 & 0.96 \\
\hline
\end{tabular}

The mean and standard deviation for the item "In the last month, how often have you been upset because of something that happened unexpectedly?" was $3.64( \pm 0.56)$ (pre) and 3.08 ( \pm 0.77) (post) respectively. The decrease in the mean score could be because the self- care program was supporting the health care workers in attenuating the perceived stress.

The mean and standard deviation pre and post the intervention for the item "In the last month, how often have you felt that you were unable to control the important things in your life?" was $3( \pm 0.94)$ (pre) and $2.68( \pm 1.08)$ (post) respectively. This reduction in the mean score could be due to the influence of the intervention in creating awareness about the pandemic and increased preparedness in handling the situation.

The mean pre and post intervention score for the item "In the last month, how often have you felt nervous and stressed" is $3.08( \pm 0.75)$ (pre) and 2.66 $( \pm 1.22)$ (post) respectively. This explains that the participants' perceived stress has reduced after the intervention. As per the literature review this may alienate chronic health problems [11, 8, 12-14].

The mean score pre and post the intervention for the item "In the last month, how often have you felt confident about your ability to handle your personal problems?" was $0.94( \pm 1.04)$ (pre) and $1.28( \pm 1.13)$ (post) respectively. This indicates an increase in the confidence in their ability to handle personal problems. This could be an interesting evidence that self-care program has been beneficial to the participants to cope with the current pandemic and the changes in the professional environment. 
The mean score pre and post the intervention for the item stating "In the last month, how often have you felt that things were going your way?" is 1.64 $( \pm 0.94)$ (pre) and $1.66( \pm 1.15)$ (post) respectively. The score has not changed considerably. This could be because of the negative emotions experienced during the pandemic and intervention [15].

The mean score pre and post the intervention for the item stating "In the last month, how often have you found that you could not cope with all the things that you had to do?" is $2.64( \pm 0.89)$ (pre) and 2.26 $( \pm 1.12)$ (post) respectively. The score has mildly reduced post the intervention. This indicates the self care program has been a representative intervention in adequately managing the coping skills of the health care workers.

The mean score pre and post the intervention for the item stating "In the last month, how often have you been able to control irritations in your life?" is 3.14 $( \pm 0.81)$ (pre) and $1.8( \pm 1.11)$ (post) respectively. This indicates that the self-care program could have induced control over irritation which might be associated with the reduction of challenges in enjoying pleasures as part of the program [16].
The mean score pre and post the intervention for the item stating "In the last month, how often have you felt that you were on top of things?" is $3.04( \pm 0.85)$ (pre) and $1.86( \pm 1.19)$ (post) respectively. There is a decrease in the mean score. This could be due to the increase in the perceived social support as part of the self-care program [17].

The mean score pre and post the intervention for the item stating "In the last month, how often have you been angered because of things that were outside of your control?" is $2.92( \pm 1.03)$ (pre) and $2.36( \pm 1.15)$ (post) respectively. This indicates that the mean score has decreased. This could be due the relaxation techniques that are practiced during the self-care program which has been 'a first time experience' of majority of the participants.

The mean score pre and post the intervention for the item stating " In the last month, how often have you felt difficulties were piling up so high that you could not overcome them?" is $2.92( \pm 1.03)$ (pre) and $2.62( \pm 0.96)$ (post) respectively. There is a decrease in the mean score. This indicates that self-care program enabled the participants to replenish physical and mental strength to take control over the difficulties.

Table-2: Paired sample statistics

\begin{tabular}{|c|c|c|c|c|c|c|}
\hline & $\mathbf{N}$ & Mean & SD & $\mathbf{t}$ & p & Cohen's d \\
\hline Pre test & 50 & 29.220 & 4.96638 & \multirow[t]{2}{*}{8.684} & .000 & \multirow[b]{2}{*}{6.05} \\
\hline Post test & 50 & 21.780 & 4.45975 & & & \\
\hline
\end{tabular}

Data presented in table 2 shows for the research sample $(\mathrm{n}=50)$, the perceived stress is high in pre-test $(29.22 \pm 4.96)$ than in post-test $(21.78 \pm 4.45)$. The $\mathrm{t}$ values is significant at 0.01 level $(\mathrm{df}=49, \mathrm{t}=8.68$, $\mathrm{p}=.000$ ). Analysis shows that samples have less stress in post-test than in pre-test, $\mathrm{p}<0.01$, hence the null hypothesis is rejected and alternate hypothesis is accepted.

Amidst the shortage of health care workers during the pandemic the work setting has been overwhelming in inducing stress [18]. A paired-samples t-test was conducted to compare the perceived stress of health care workers of people with dementia pre and post the self-care program during the Covid19 pandemic. On an average the perceived stress was higher in the participants prior to the intervention.

The data shown in table 2 suggests that the self-care program does have a huge effect on reducing the perceived stress of the health care workers during the pandemic. In summary, the study has shown the inevitable benefits of self-care program in modifying aspects of training for the health care workers by identifying perceived stress in maintaining greater personnel strength and their health promotion.

\section{CONCLUSION}

It can be concluded that the perception of stress in health care workers is related to specific professional characteristics, gender and also the extent of team work with pleasurable experiences in a particular setting. Self-care program aids in subsiding the levels of perceived stress even in situations demanding high levels of occupational dedication in health care workers.

The results of this study may contribute in formulating future policies on the health care workers in the residential care setting, introducing cost-effective training to prevent occupational distress within the Indian health system. Future studies can also focus on interrelationship improvement between health care workers and residents in the long term care units in reducing perceived stress.

\section{ACKNOWLEDGMENTS}

The author(s) profoundly appreciate all the people who have successfully contributed in ensuring this paper in place. Their contributions are acknowledged however their names cannot be mentioned. 


\section{Conflict of interest}

There is no conflict of interest

\section{REFERENCES}

1. Scott, J. P., \& Caldwell, J. (1996). Needs and program strengths: perceptions of hospice volunteers. The Hospice Journal, 11(1), 19-30.

2. Keefe, J., \& Fancey, P. (2000). The care continues: Responsibility for elderly relatives before and after admission to a long term care facility. Family Relations, 49(3), 235-244.

3. Dilworth-Anderson, P., \& Gibson, B. (1999). Ethnic Minority Perspectives on Dementia, Family Caregiving, and Interventions. Generations: Journal of the American Society on Aging, 23(3), 40-45.

4. Quintiliani, L. J., \& Sattelmair, G. S. (2007). The workplace as a setting for interventions to improve diet and promote physical activity. Retrieved from http://www.who.int/dietphysicalactivity/Quintiliani -workplace-as-setting.pdf

5. Cohen, S., Kamarck, T., Mermelstein, R. (1983). A global measure of perceived stress. Journal of Health and Social Behavior, 24, 385-396.

6. Selye, H. (1946). The general adaptation syndrome and the diseases of adaptation. The journal of clinical endocrinology, 6(2), 117-230.

7. Pais Ribeiro, J., \& Marques, T. (2009). The stress assessment: about a study of adaptation of the stress perception scale. Psychology, Health \& Diseases, 10(2), 237-248.

8. Dawe, K., Montgomery, A., McGee, H., Panagopoulou, E., Morgan, K., Hackshaw, L., \& Vedhara, K. (2016). The effects of perceived stress on biological parameters in healthcare professionals: A systematic review. Journal of health psychology, 21(5), 607-618.

9. Camelo, S.H.H., \& Angerami, ELS (2008). Psychosocial risks at work that can lead to stress: a literature analysis,; - DOI: 10.4025 / cienccuidsaude.v7i2.5010. Science, Care and Health, 7(2), 234-240.
10. Tomasi, E., Facchini, L. A., Piccini, R. X., Thumé, E., Silveira, D. S. D., Siqueira, F. V., ... \& Teixeira, V. A. (2008). Socio-demographic and epidemiological profile of primary health care workers in the South and Northeast regions of Brazil. Cadernos de Saúde Pública, 24 (Suppl. 1), s193-s201.

11. Andreou, E., Alexopoulos, E. C., Lionis, C., Varvogli, L., Gnardellis, C., Chrousos, G. P., \& Darviri, C. (2011). Perceived Stress Scale: reliability and validity study in Greece. International journal of environmental research and public health, 8(8), 3287-3298.

12. Irving, J. A., Dobkin, P. L., \& Park, J. (2009). Cultivating mindfulness in health care professionals: a review of empirical studies of mindfulness-based stress reduction (MBSR). Complementary therapies in clinical practice, 15(2), 61-66.

13. Leonelli, L. B., Andreoni, S., Martins, P., Kozasa, E. H., Salvo, V. L. D., Sopezki, D., ... \& Demarzo, M. M. P. (2017). Perceived stress among primary health care professionals in Brazil. Revista Brasileira de Epidemiologia, 20, 286-298.

14. Vahey, D. C., Aiken, L. H., Sloane, D. M., Clarke, S. P., \& Vargas, D. (2004). Nurse burnout and patient satisfaction. Medical care,42(2 Suppl), II57-II66.

15. Snippe, E., Dziak, J. J., Lanza, S. T., Nyklíček, I., \& Wichers, M. (2017). The shape of change in perceived stress, negative effects, and stress sensitivity during mindfulness-based stress reduction. Mindfulness, 8(3), 728-736.

16. Berenbaum, H., \& Connelly, J. (1993). The effect of stress on hedonic capacity. Journal of Abnormal Psychology, 102(3), 474-481.

17. Stansfeld, S. A., Rael, G. S., Head, J., Shipley, M., \& Marmot, M. (1997). Social support and psychiatric sickness absence: a prospective study of British civil servants. Psychological medicine, 27(1), 35-48.

18. Pearlin, L. I., \& Schooler, C. (1978). The structure of coping. Journal of Health and Social Behavior, 19(1), 2-21. 